\title{
O Brilhantismo de Turgot - Parte II
}

\author{
Murray N. Rothbard ${ }^{* *}$
}

\begin{abstract}
Resumo: Neste artigo, o autor apresenta e discute a importância do pensamento de Anne Robert Jacques Turgot para a História do Pensamento Econômico. Destaca seu brilhantismo intelectual, sua defesa da economia de mercado e do livre comércio, e suas contribuições protagonistas para as teorias do valor, das trocas, dos preços, da produção e da distribuição.
\end{abstract}

Palavras-Chave: Turgot, Laissez-faire, Comércio, Preços, Valor, Produção, Distribuição.

\section{The Brilliance of Turgot - Part II}

Abstract: In this article, the author presents and discusses the importance of the thought of Anne-Robert-Jacques Turgot for the History of Economic Thought. He highlights Turgot's intellectual brilliance, his defense of the market economy and of free trade, and his early contributions to the theories of value, trade, prices, production and distribution.

Keywords: Turgot, Laissez-faire, Trade, Prices, Value, Production, Distribution.

Classificação JEL: B10, B31.

\footnotetext{
" O presente artigo é a segunda metade do seguinte ensaio: ROTHBARD, Murray N. The Brilliance of Turgot. In: An Austrian Perspective on the History of Economic Thought - Volume I: Economic Thought Before Adam Smith. Auburn: Ludwig von Mises Institute, 2006. p. 381-413. A primeira parte do texto foi publicada na edição anterior de MISES: Revista Interdisciplinar de Filosofia, Direito e Economia.

Traduzido do inglês para o português por Márcia Xavier de Brito.

** Murray N. Rothbard nasceu em 2 de março de 1926, no Bronx, em Nova York. Graduou-se em Matemática em 1945, na Columbia University, por onde também recebeu, em 1956, o título de Doutor em Economia. Lecionou no Brooklyn Polytechnic Institute, de 1964 a 1986, e na escola de negócios da University of Nevada, em Las Vegas, de 1986 até a morte, em 1995. Rothbard foi o fundador e principal teórico do anarcocapitalismo, um firme defensor do revisionismo histórico e uma figura central no movimento libertário norte-americano do século XX. É autor de mais de vinte livros, dentre os quais se destacam o tratado de economia Man, Economy, and State e Governo e Mercado (Instituto Ludwig von Mises Brasil, 2012). Faleceu no dia 7 de janeiro de 1995 em Nova York, nos Estados Unidos.
} 


\section{V- A Teoria do Capital, Empreendedorismo, Poupança e Juros}

No rol das extraordinárias contribuições de Anne Robert Jacques Turgot (1727-1781) para a teoria econômica, a mais notável é a teoria do capital e dos juros que, em comparação com esferas como a da utilidade, aflorou praticamente desenvolvida, sem referência às contribuições precedentes. Não só isso: Turgot elaborou de modo quase completo a teoria austríaca do capital e dos juros antes demonstrada de forma definitiva por Eugen Böhm-Bawerk (1851-1914).

A adequada teoria do capital fez eco nos economistas clássicos britânicos, bem como nos austríacos. Assim, na grande obra Réflections, Turgot assinalou que a riqueza é acumulada por intermédio do produto não consumido e poupado anualmente. As poupanças são acumuladas em forma de moeda e, então, investidas em vários tipos de bens de capital. Além disso, como ressaltou Turgot, o capitalista-empreendedor deve primeiro acumular o capital poupado para "adiantar" o pagamento dos trabalhadores enquanto o produto é trabalhado. Na agricultura, o capitalista-empreendedor deve reservar fundos para pagar aos trabalhadores, comprar gado, pagar por instalações e equipamento, etc., até que seja feita e vendida a colheita, quando pode reaver os adiantamentos. E assim acontece em todos os campos de produção.

Alguma coisa disso foi captada por Adam Smith (1723-1790) e pelos classicistas britânicos posteriores. No entanto, eles deixaram de assimilar dois pontos vitais. O primeiro é o fato do capitalista de Turgot ser também um capitalista-empreendedor. Ele não só adianta a poupança para os trabalhadores e outros fatores de produção como também, como mostrou Richard Cantillon (1680-1734) pela primeira vez, suporta os riscos da incerteza no mercado. A teoria de Cantillon do empresário como um tomador de risco universal a enfrentar a incerteza, equilibrando, assim, as condições do mercado carecia de um elemento-chave: uma análise do capital e a percepção de que a principal força motriz da economia de mercado não é qualquer empreendedor, mas o capitalista-empreendedor, o homem que combina ambas as funções ${ }^{1}$. Contudo, o feito memorável de Turgot ao desenvolver a teoria do capitalista-empreendedor tem sido, como recorda o professor Berthold F. Hoselitz (1913-1995), completamente ignorada até o século $X^{2}$.

Se os classicistas britânicos negligenciaram completamente o empreendedor, também erraram ao não assimilar a ênfase protoaustríaca de Turgot sobre o papel crucial do tempo na produção e no fato das indústrias requererem muitos estágios de produção com longos períodos de pagamentos adiantados antes da produção e venda. Turgot, perceptivamente, destacou que é o dono do capital:

que esperará que a venda dos couros the renda não somente todos os seus investimentos, mas ainda lucro suficiente para indenizá-lo do que the teria valido seu dinheiro se o tivesse aplicado em aquisição de fundos, e ademais pelo soldo devido por seus trabalhos, por seus cuidados, por seus riscos, por sua perícia mesma $[\ldots]^{3}$.

${ }^{1}$ Em um trabalho recente muito esclarecedor sobre a história da teoria do empreendedor, os professores Robert F. Hébert e Albert N. Link analisam o problema de se o empreendedor é somente um capitalista ou se qualquer pessoa, dentre elas trabalhadores sem capital, são empreendedores. Turgot é tido como alguém afastado do conceito amplo de empreendedor de Cantillon, mas o ponto importante aqui é que o capitalista-empreendedor é a força motriz da economia de mercado e que, pela primeira vez, essa figura importante foi destacada. Turgot deu um enorme passo à frente e todos saudamos seu feito, mesmo se for igualmente verdade que Turgot negligenciou áreas mais amplas e menos importantes do empreendedorismo. Ver: HÉBERT, Robert F. \& LINK, Albert. N. The Entrepreneur: Mainstream Views and Radical Critiques. New York: Praeger, 1982. p. 14-29 et passim.

${ }^{2}$ HOSELITZ, B. F. The Early History of Entrepreneurial Theory. In: SPENGLER, Joseph J. \& ALLEN, William R. (Eds.). Essays in Economic Thought. Chicago: Rand McNally, 1960. p. 257.

${ }^{3}$ TURGOT, A. R. J. Reflexões Sobre a Formação e a Distribuição das Riquezas. In: MISES: Revista 
Nessa passagem, Turgot antecipou o conceito austríaco de custo de oportunidade e nota que o capitalista tenderá a ganhar as retribuições atribuídas e a oportunidade que sacrificou por não investir seu dinheiro em nenhum outro local. Em suma, os lucros contábeis do capitalista tenderão a um equilíbrio de longo prazo acrescido das retribuições atribuídas pelo seu próprio trabalho e habilidades. Na agricultura, na manufatura ou em qualquer outro campo de produção existem duas classes básicas de produtores na sociedade: os empresários, donos do capital, "que aplicam dando trabalho, por meio de seus investimentos" e os trabalhadores ou "simples artesãos que não possuem outros bens além de seus braços, que não investem senão seu trabalho diário, que não auferem senão seus salários" ${ }^{4}$.

Nessa ocasião, Turgot incorporou o germe de uma valiosa percepção do Tableau fisiocrata - de que o capital investido deve continuar a dar um lucro estável pela circulação contínua de despesas, do contrário, ocorrerão deslocamentos na produção e pagamentos. Ao integrar suas análises de moeda e capital, Turgot então ressaltou que, antes da evolução do ouro e da prata como moeda, o escopo para empreender, manufaturar e comercializar era muito limitado. Para desenvolver a divisão de trabalho e os estágios de produção é necessário acumular grandes somas de capital e realizar vastas trocas, nenhum dos quais é possível sem moeda.

Vendo que "adiantamentos" das poupanças para fatores de produção são uma chave para o investimento e que esse processo só é desenvolvido numa economia monetária, Turgot então seguiu adiante até chegar a um ponto "austríaco" crucial: já que adiantamentos de moeda e capital são indispensáveis a todos os empreendimentos, os trabalhadores, portanto, estão dispostos a pagar ao capitalista um desconto da produção pelo serviço

Interdisciplinar de Filosofia, Direito e Economia. Vol. III, No. 2 (Ed. 06, Jul-Dez. 2015). LX. p. 483.

${ }^{4}$ Idem. Ibidem. LXI. p. 483. de ter o dinheiro pago a eles adiantadamente pela receita futura. Em suma: o retorno dos juros sobre o investimento (o que o "austríaco" sueco Knut Wicksell (1851-1926) chamaria um século depois de "taxa de juros natural") é o pagamento pelos trabalhadores aos capitalistas pela função de adiantá-los em dinheiro presente de modo que não tenham de esperar por anos para ter uma receita. Como Turgot apresenta nas suas Réflections:

Já que os capitais são a base indispensável de todo e qualquer empreendimento lucrativo, $[\ldots]$ aqueles que, com indústria e amor ao trabalho, não têm capitais ou não os têm bastantes para os empreendimentos que querem formar não têm dificuldade em contentar-se com ceder, aos possuidores de capitais ou de dinheiro que lhos querem confiar, parte dos lucros que esperam recolher para além do retorno de seus investimentos 5 .

No ano seguinte, nos comentários brilhantes sobre o escrito de Jean-Nicolas-Marcellin Guérineau de Saint-Péravy (17351789), Turgot expandiu sua análise de poupança e capital para demonstrar o que vem a ser uma excelente antecipação da lei de Say. Turgot rejeitou os temores pré-keynesianos dos fisiocratas de que o dinheiro não gasto no consumo "escoaria" do fluxo circular e assim destruiria a economia. Como resultado disso, os fisiocratas tendiam a se opor à poupança per se. Turgot, no entanto, assinalava que os adiantamentos de capital são vitais em todos os empreendimentos e de onde mais poderiam vir senão da poupança? Notou também que não fazia diferença se tais poupanças fossem providas por proprietários de terras ou por empreendedores. Para as poupanças dos empreendedores serem grandes o bastante para acumular e expandir o capital, os lucros tem de ser mais altos que a quantia necessária para reproduzir o atual gasto do empreendimento (isto é, repor o inventário, os bens de capital, etc. assim que são sacados ou gastos).

${ }^{5}$ Idem. Ibidem. LXX. p. 483. 
Turgot prossegue destacando que os fisiocratas pressupõem, sem prova, que a poupança simplesmente escoa da circulação e diminui os preços. Ao contrário, o dinheiro volta à circulação e a poupança imediatamente será usada seja para comprar terra, para ser investida em adiantamentos para trabalhadores e outros fatores ou para ser emprestada a juros. Todos esses usos da poupança retornam o dinheiro ao fluxo circular. Adiantamentos de capital, por exemplo, retornam à circulação ao pagar equipamentos, instalações, matérias-primas ou salários. A compra da terra transfere dinheiro para o vendedor da terra, que por sua vez comprará alguma coisa com o dinheiro, pagará débitos ou reemprestará o montante. De qualquer maneira, o dinheiro retorna prontamente para a circulação. Se pegarem emprestado para pagar débitos ou comprar terra, a mesma coisa acontece. E se empreendedores pegarem emprestado o dinheiro, eles o lançarão em adiantamentos e investimentos e o dinheiro novamente voltará à circulação.

O dinheiro poupado, portanto, não é perdido, retorna à circulação. Ademais, o valor da poupança investida em capital é muito maior que o acumulado em reservas, de modo que o dinheiro tenderá a retornar à circulação rapidamente. Além disso, ressalta Turgot, mesmo se a poupança aumentada na verdade retirar uma pequena parcela do dinheiro de circulação por um tempo considerável, o menor preço do produto será mais que compensado para o empreendedor pelos adiantamentos aumentados e, consequentemente, uma maior produção e diminuição do custo de produção. Aqui, Turgot produziu a semente do que muito mais tarde a análise de Ludwig von Mises (1881-1973) e Friedrich A. Hayek (1899-1992) de como a poupança diminui, mas prolonga a estrutura da produção.

O auge da contribuição de Turgot à teoria econômica foi sua sofisticada análise de juros. Já vimos a notável percepção de Turgot ao ver o retorno de juros sobre o investimento como o preço pago pelos trabalhadores para capitalistas-empreendedores por adiantamentos de poupança em forma de dinheiro presente. Turgot também demonstrou - adiante do seu tempo - o relacionamento entre essa taxa de juros natural e os juros de empréstimos em dinheiro. Mostrou, por exemplo, que os dois tendem a ser iguais no mercado, já que os proprietários do capital equilibrarão continuamente os retornos esperados em canais diferentes de uso, sejam empréstimos em dinheiro ou investimentos diretos na produção. $\mathrm{O}$ prestamista vende o uso de seu dinheiro agora e o tomador do empréstimo compra esse uso, o preço desse empréstimo, isto é, a taxa de juros do empréstimo, será determinada, como no caso de qualquer bem, pela variações na oferta e na demanda no mercado. Se aumentar a demanda por empréstimos (muitos tomadores), crescerão as taxas de juros; se aumentar a demanda de empréstimos (muitos prestamistas), elas diminuirão. A pessoas tomam empréstimos por muitas razões, como vimos: para tentar ter um lucro empresarial, para comprar terra, pagar débitos ou consumo; ao passo que prestamistas estão preocupados apenas com dois assuntos: retorno dos juros e a segurança do capital.

Muito embora exista uma tendência do mercado para equacionar as taxas de juros de empréstimo e de retorno de juros e investimentos, os empréstimos tendem a ser a maneira menos arriscada de canalizar a poupança. Assim, investimentos em empreendimentos arriscados só serão feitos se os empreendedores esperarem que seus lucros sejam maiores que a taxa de juros do empréstimo. Turgot também assinala que os títulos do governo tenderão a ser um investimento menos arriscado, de modo que terão o menor retorno dos juros. Prossegue e declara que o "verdadeiro" mal do débito do governo é apresentar vantagens aos credores públicos, contudo, canalizando as poupanças para usos "estéreis" e improdutivos e mantendo uma alta taxa de juros competindo com usos produtivos (ou, como diríamos atualmente, o débito público "impede a entrada" de usos produtivos das poupanças privadas). 
Insistindo na análise da natureza e uso do empréstimo a juros, Turgot ocupou-se de uma crítica incisiva e contundente das leis da usura que os fisiocratas ainda tentavam defender.

Um empréstimo, assinalou Turgot, "éum contrato recíproco, livre entre as duas partes, e que não é celebrado senão porque lhes é vantajoso"6. Todavia, um empréstimo contratado é, então, vantajoso ipso facto para ambas as partes: tanto para o prestamista quanto para o tomador do empréstimo. Turgot chega ao argumento decisivo: "ora, de acordo com que princípio se pode imaginar um crime em um contrato vantajoso para as duas partes em que os dois estão contentes e que certamente não prejudica a ninguém mais?"7 Não há exploração em cobrar juros, assim como isso não existe na venda de nenhum bem. Atacar o prestamista por levar vantagem da necessidade de dinheiro do tomador de empréstimo "é dizer tanta absurdidade como se se dissesse que um padeiro que exige dinheiro em troca do pão que vende abusa da necessidade que tem o comprador"s.

E, se o dinheiro gasto no pão for considerado seu equivalente, então, da mesma maneira, "o dinheiro que o tomador recebe hoje é também equivalente ao capital e aos juros que ele promete devolver em certo tempo" 9 . Em suma, um contrato de empréstimo estabelece o valor presente de um pagamento futuro de capital e juros. O tomador tem o uso do dinheiro durante o termo do empréstimo; o prestamista é privado de tal uso; o preço dessa vantagem ou desvantagem são os juros.

É verdade, diz Turgot à ala antiusura dos escolásticos, que o dinheiro como "massa de metal"10 é estéril e nada produz, mas o dinheiro empregado com sucesso em empreendimentos gera lucro ou, investido na terra,

\footnotetext{
${ }^{6}$ Idem. Ibidem. LXXIII. p. 488.

${ }^{7}$ Idem. Ibidem. LXXIII. p. 488-89.

${ }^{8}$ Idem. Ibidem. LXXIII. p. 489.

${ }^{9}$ Idem. Ibidem. LXXIII. p. 489.

${ }^{10}$ Idem. Ibidem. LXXIII. p. 489.
}

gera receita. O prestamista abre mão, durante o termo do empréstimo, não só da posse do metal, mas do lucro que poderia ter obtido por investi-lo: "do lucro ou do rendimento que poderia ter obtido, e os juros que o indenizam dessa privação não poderiam ser vistos como injustos" 11. Assim, Turgot integra sua análise e justificativa pelos juros com a visão generalizada de custo de oportunidade, da perda de rendimentos por emprestar dinheiro. E então, sobretudo, Turgot declara que existe direito de propriedade do prestamista, um ponto crucial que não deve ser subestimado. O prestamista tem o

direito de exigir juros sobre o empréstimo pela simples razão de que seu dinheiro lhe pertence. Já que lhe pertence, é livre para guardá-lo; nada o obriga a emprestá-lo: se então o empresta, pode atribuir a seu empréstimo a condição que quiser. Não faz com isso mal algum ao tomador, já que este se submete a tal condição e não tem nenhuma espécie de direito sobre a soma emprestada $^{12}$.

Quanto à passagem bíblica em Lucas que, por séculos, foi usada para denunciar os juros, a passagem que fala de empréstimos sem ganho ${ }^{13}$, Turgot nota que esse conselho era simplesmente um preceito de caridade, uma "ação louvável inspirada pela generosidade"14 e não uma exigência da justiça. Os adversários

${ }^{11}$ Idem. Ibidem. LXXIII. p. 489.

${ }^{12}$ Idem. Ibidem. LXXIV. p. 489-90.

${ }^{13}$ A passagem referida encontra-se em Lc 6,36 e diz: "emprestai, sem daí esperar nada". Sobre a proibição canônica da usura, ver: ROTHBARD, Murray N. O Pensamento Econômico na Idade Média - Parte I. Trad. Márcia Xavier de Brito. MISES: Revista Interdisciplinar de Filosofia, Direito e Economia, Vol. I, No. 1 (jan.-jun. 2013): p.117-122 e ROTHBARD, Murray N. O Pensamento Econômico na Idade Média Parte II. Trad. Márcia Xavier de Brito. MISES: Revista Interdisciplinar de Filosofia, Direito e Economia, Vol. I, No. 2 (jul.-dez. 2013): 477- 490. [N. do T.]

${ }^{14}$ No original: "est une action louable que la générosité inspire". TURGOT, A. R. J. "Mémoire sur les prêts d'argent". In: Oeuvres de Turgot. Ed. Eugène Daire. Vol. 1. Paris: Guillaumin, [1770] 1844. p. 121. [N. do T.] 
da usura, explicou Turgot, nunca apresentaram com firmeza uma posição consistente ao tentar forçar a todos a emprestar suas poupanças a juros zero.

Numa das últimas contribuições, o altamente influente Memorando Sobre o Empréstimo de Dinheiro ${ }^{15}$ de 1770, Turgot elaborou sua crítica às leis da usura. Ao mesmo tempo, ampliou a notável teoria dos juros ${ }^{16}$. Notou que as leis da usura não são rigorosamente aplicadas, o que leva à disseminação de um mercado negro nos empréstimos. No entanto, o estigma da usura permanece, juntamente com a desonestidade pervasiva e o desrespeito à lei. Ainda, de vez em quando, as leis da usura são aplicadas de modo esporádico e imprevisível, com penas severas.

Mais importante, Turgot nesse Mémoire concentrou-se no problema crucial dos juros: Por que os tomadores de empréstimo estão dispostos a pagar um ágio de juros pelo uso do dinheiro? Os adversários da usura, observou, defendem que o prestamista, ao exigir mais que o principal a ser devolvido, está recebendo um valor excedente ao valor do empréstimo e tal excedente é, de algum modo, excessivamente imoral. Entretanto, Turgot toca num ponto crucial: "É certo que, ao pagar o principal, o tomador do empréstimo devolva exatamente o mesmo peso de metal que o prestamista lhe deu" ${ }^{\prime 17}$. No entanto, acrescenta, não deveria o peso do metal ser a consideração crucial e não "o valor, ou melhor, a utilidade que possui para o que empresta e para o que

\footnotetext{
15 “Mémoire sur les prêts d'argent". [N. do T.]

${ }^{16} \mathrm{O}$ ensaio de Turgot foi elogiado no notável ensaio de Jeremy Bentham (1748-1832), Defence of Usury, e foi reimpresso juntamente com o ensaio de Bentham nas traduções francesas e espanholas no final da década de 1820.

${ }^{17}$ No original: "il est certain qu'en rendant le sort principal, l'emprunteur rendra précisément le Même poids de métal que le prêteur lui avait donné". TURGOT, A. R. J. "Mémoire sur les prêts d'argent". In: Oeuvres de Turgot. Ed. Eugène Daire. Vol. 1. Paris: Guillaumin, [1770] 1844. p. 127. [N. do T.]
}

toma emprestado?"18 Especificamente, ao chegar ao conceito Böhm-bawerkiano-austríaco de preferência temporal, Turgot nos incita a comparar "a diferença em utilidade que existe na data do empréstimo entre a soma atualmente possuída e um montante igual a ser recebido numa data distante" ${ }^{\prime 1}$. A chave é a preferência temporal - o desconto do fututo e a colocação concomitante de uma recompensa no presente. Turgot faz referência ao conhecido ditado: "mais vale um pássaro na mão que dois voando" 20 . Já que a soma do dinheiro é possuída na verdade agora, "é preferível a segurança de receber uma soma semelhante no período de um ou vários anos" 21 . A mesma soma de dinheiro paga e retornada dificilmente é um valor equivalente, pois o prestamista "dá $o$ dinheiro e recebe somente uma certeza"22. Entretanto, essa perda em valor não pode "ser compensada pela certeza de um aumento na soma proporcionada pela demora?" ${ }^{23}$. Turgot conclui

\footnotetext{
${ }^{18}$ No original: "la valeur, ou plutôt l'utilité dont il est pour celui qui prête et pour celui qui emprunte?". Ibidem, p. 127. [N. do T.]

${ }^{19}$ No original: "sans comparer la différence d'utilité qui se trouve à l'époque du prêt entre une somme possédée actuellement et une somme égale qu'on recevra dans une époque éloignée". Ibidem, p. 127. [N. do T.]
}

${ }^{20}$ No original: "un tiens vaut mieux que deux tu l'auras". A expressão em francês foi popularizada por Jean de La Fontaine (1621-1695) na fábula “O peixinho e o pescador", cuja tradução do trecho em português parece bastante elucidativa para o caso em questão: "um 'Toma' vale no mundo / mais do que dois te darei / O 'Toma' é sempre seguro, / Quanto ao segundo... não sei." In: “O Peixinho e o Pescador". Trad. Barão de Paranapiacaba. Fábulas de La Fontaine. Apres. e sel. João Alves das Neves. São Paulo: Edições Melhoramentos, 1962. p. 211. [N. do T.]

${ }^{21}$ No original: "elle est préférable à l'assurance de recevoir une pareille somme dans une ou plusieurs années". TURGOT, A. R. J. "Mémoire sur les prêts d'argent". Op. cit. p. 127. [N. do T.]

${ }^{22}$ No original: “donne de l'argent et ne reçoit qu'une promesse". Ibidem, p. 127. [N. do T.]

${ }^{23}$ No original: "ne serait-elle pas compensée par l'assurance d'une augmentation sur la somme, proportionnée au retard?". Ibidem, p. 127. [N. do T.] 
que "essa compensação é precisamente o juro do dinheiro" ${ }^{24}$. Acrescenta que o que tem de ser comparado numa transação de empréstimo não é o valor do dinheiro emprestado com a soma retribuída, mas "o valor da promessa de uma soma de dinheiro comparada ao valor do dinheiro agora disponível" 25 . Um empréstimo é exatamente a transferência de uma soma de dinheiro em troca de uma promessa atual de uma soma de dinheiro futura. Por isso, uma taxa máxima de juros imposta pela lei privaria de crédito praticamente todos os empreendimentos arriscados.

Além de desenvolver a teoria de preferência temporal austríaca, Turgot foi a primeira pessoa, nas Réflections, a apontar o conceito correspondente de capitalização, ou seja, o valor presente do capital da terra ou de outro bem no mercado tende a se igualar à soma dos rendimentos ou retornos futuros anuais esperados, descontada a taxa de mercado da preferência temporal, ou taxa de juros ${ }^{26}$.

Como se isso não bastasse como contribuição à Economia, Turgot também foi o pioneiro na análise sofisticada da interrelação entre taxa de juros e a "teoria quantitativa" da moeda. Existe pouca relação, assinala, entre o valor da moeda corrente em termos de preços e a taxa de juros. A oferta de moeda pode ser abundante e por isso o valor da moeda baixo em termos de bens, mas os juros podem,

\footnotetext{
${ }^{24}$ No original: "Cette compensation est précisément l'intérêt de l'argent". Ibidem, p. 127. [N. do T.]

${ }^{25}$ No original: "c'est la valeur de la promesse d'une somme d'argent qu'il faut comparer avec une somme d'argent effective". Ibidem, p. 130. [N. do T.]

${ }^{26}$ Como diz Turgot: "um capital é equivalente a uma renda igual a determinada porção de tal capital; e, reciprocamente, uma renda anual representa um capital igual ao montante dessa renda repetida certo número de vezes, segundo os juros estejam mais ou menos altos" ("un capital est l'équivalent d'une rente égale à une portion déterminée de ce capital, et réciproquement une rente anuelle représente un capital égal au montant de celle rente répété un ceertain nombre de fois, suivant que l'intérêt est à un denier plus ou moins haut"). TURGOT. Reflexões Sobre a Formação e a Distribuição das Riquezas. LXXVII. p. 491
}

ao mesmo tempo, ser muito altos. Talvez seguindo um modelo semelhante ao de David Hume (1711-1776), Turgot pergunta o que poderia acontecer se a quantidade de moeda de prata em um país, de repente, dobrasse $e$ esse aumento fosse magicamente distribuído em proporções iguais para todas as pessoas. De modo específico, Turgot nos pede para pressupor que há um milhão de onças de moedas de prata em um país e "suponha-se que surja no Estado, por qualquer razão, um segundo milhão de onças, e que esse aumento se distribua entre todos segundo a mesma proporção do primeiro milhão, de modo que aquele que possuía anteriormente duas onças tenha agora quatro" 27 . Turgot, então, explica que os preços subirão, talvez dobrem, e que, portanto, o valor da prata em termos de bens cairá. Acrescenta, todavia, que isso não significa de modo algum que cairá a taxa de juros, caso as proporções de gastos das pessoas continuem as mesmas, "se todo esse dinheiro é levado ao mercado e usado nas despesas correntes daqueles que o possuem" ${ }^{28}$. O novo dinheiro não será emprestado, uma vez que somente o dinheiro poupado é emprestado e investido.

De fato, Turgot nota que, dependendo de como as proporções de gasto-poupança são afetadas, um aumento na quantidade de moeda pode elevar as taxas de juros. Suponhamos, diz, que todas as pessoas ricas decidam gastar suas receitas e lucros anuais em consumo e gastem o capital em despesas tolas. $\mathrm{O}$ maior gasto em consumo aumentará os preços dos bens de consumo e, restando muito

27 No original: “je suppose qu'il survienne, de quelque manière qui ci soit, dans l'État un second million d'onces d'argent, et que cette augmentation soit distribuée dans toutes les bourses suivant la même proportion que le premier million, en sorte que celui qui avait précédemment deux onces d'argent en ait maintenant quatre". Idem. Ibidem. LXVIII. p. 491.

${ }^{28}$ Embora o modelo Hume-Turgot seja altamente útil para separar e esclarecer distinções entre nível de preço e juros e destacar o impacto de uma mudança na quantidade de moeda, ainda é um retrocesso do sofisticado processo de análise de Cantillon. No original: "si tout cet argent est porté au marché et employé aux dépenses courantes de ceux que le possèdent". Idem. Ibidem. LXVIII. p. 492. 
menos dinheiro para emprestar ou investir, as taxas de juros se elevarão juntamente com os preços. Em suma, o gasto acelerará a subida dos preços, enquanto que, ao mesmo tempo, quando sobem as taxas de preferência temporal, as pessoas gastam mais e poupam menos, produzindo o aumento das taxas de juros. Assim, Turgot está mais de um século à frente de seu tempo ao desenvolver o sofisticado relacionamento austríaco entre aquilo que Mises chamaria de "relação-moeda" - a relação entre a oferta e a demanda por moeda, que determina preços ou o nível de preço - e as taxas de preferência temporal que determinam a proporção gasto-poupança e a taxa de juros. Aqui, também, estavam os rudimentos da teoria austríaca da teoria dos ciclos econômicos, da relação entre a expansão da oferta de moeda e a taxa de juros.

Quanto aos movimentos na taxa de preferência temporal ou juros, um aumento no espírito de parcimônia diminuirá as taxas de juros e aumentará a quantidade de poupança e a acumulação de capital. Um aumento no espírito de luxo fará o oposto. O espírito de parcimônia, observa Turgot, foi constantemente aumentando na Europa por vários séculos e, por isso, as taxas de juros tendiam a cair. As várias taxas de juros e taxas de retorno dos empréstimos, investimentos, terras, etc. tenderão a se equilibrar em todo o mercado e buscarão a direção de uma taxa única de retorno de capital. O capital, diz Turgot, transferir-se-á das indústrias e regiões de menor lucratividade para as indústrias de maior lucratividade.

\section{VI- Teoria da Moeda}

Embora Turgot não tenha propriamente dedicado muita atenção à teoria da moe$\mathrm{da}$, fez algumas contribuições importantes. Além disso, ao dar continuidade ao modelo de Hume e integrá-lo com suas análises dos juros, Turgot foi enfático na oposição à ideia, agora dominante, de que a moeda é um penhor puramente convencional. Na crítica de um ensaio premiado de Jean Joseph L. Graslin (1728-1790), de 1767, Turgot declara que Graslin está totalmente equivocado ao "considerar a moeda como um penhor convencional das riquezas" 29 . Ao contrário, Turgot declara: "não é de modo algum por virtude de uma convenção que a moeda é trocada por todos os outros valores: ela é, em si mesma, um objeto de comércio, uma forma de riqueza porque tem um valor e porque todos os valores se dão em troca, no comércio, por um valor igual" 30 .

Em um artigo inacabado para um dicionário sobre Valor e Moeda, Turgot desenvolve ainda mais sua teoria da moeda. Tendo por base seu conhecimento de linguística, declara que a moeda é uma espécie de linguagem, que dá forma a várias coisas convencionais transformando-as em "um termo ou padrão comum" $^{\prime 31}$. O termo comum de todas as moedas correntes é o valor real ou preço dos objetos que tentam medir. Essas "medidas", no entanto, dificilmente são perfeitas, reconhece Turgot, já que os valores de ouro e prata sempre variam em relação aos bens, assim como variam com relação uns aos outros. Todas as moedas são feitas dos mesmos materiais, grande parte de ouro e prata, e diferem somente em unidades de moeda corrente. Todas essas unidades são redutíveis umas às outras, assim como o são outras medidas de comprimento ou volume, por expressões de peso em cada moeda corrente padrão. Existem dois tipos de moeda, observa Turgot, a moeda real moedas, peças de metal marcadas com inscrições - e as moedas fictícias, que servem como

\footnotetext{
${ }^{29}$ No original: “L'auteur se trompe beaucoup en ne regardant l'argent que comme un gage conventional des richesses". TURGOT. A. R. J. "Observation sur une mémoire de M. Graslin". In: Oeuvres de Turgot. Ed. Eugène Daire. Vol. 1. Paris: Guillaumin, [1770] 1844. p. 439. [N. do T.]

${ }^{30}$ No original: "Ce n'est point $d u$ tout en vertu d'une convention, que l'argent s'échange contre toutes les autres valeurs: c'est parce qu'il est lui-même un objet de commerce, une richesse, parce qu'il a une valeur, et que toute valeur s'échange dans le commerce contre une valeur égale". Ibidem. p. 439-40. [N. do T.]

${ }^{31}$ No original: "terme ou étalon comun". TURGOT. A. R. J. “Valeurs et monnaies". In: op. cit. p. 75. [N. do T.]
} 
unidades contábeis ou numéraires. Quando as verdadeiras unidades de moeda real são definidas em termos de unidades contábeis, as várias unidades estão, nessa ocasião, ligadas umas às outras e a pesos específicos de ouro e prata.

Surgem problemas, mostra Turgot, porque as moedas reais no mundo não são apenas um metal, mas dois - ouro e prata. Os valores relativos de ouro e prata no mercado variarão de acordo com a abundância e a escassez relativa de ouro e prata nas várias nações.

\section{VII- INFLUÊNCIA}

Um dos exemplos mais surpreendentes de injustiça na historiografia da Economia é o tratamento dado às brilhantes análises de Turgot de capital e juros feitas pelo grande fundador da teoria do capital e dos juros, Eugen von Böhm-Bawerk. Na década de 1880, Böhn-Bawerk, no primeiro volume de sua obra Capital e Juros, abriu caminho para sua teoria dos juros estudando e demolindo as teorias anteriores e rivais. Infelizmente, em vez de reconhecer Turgot como seu precursor enquanto pioneiro da teoria austríaca, Böhm-Bawerk repudiou bruscamente o francês como um mero teórico fisiocrata ingênuo que acreditava na produtividade da terra (ou 'frutificação'). Essa injustiça com Turgot fica ainda mais agravada pela recente informação de que Böhm-Bawerk, na primeira avaliação da teoria dos juros de Turgot em um ensaio não publicado de um seminário em 1876, revela a enorme influência das visões de Turgot no pensamento desenvolvido posteriormente. Talvez devamos concluir que, nesse caso, como em outros casos, a necessidade de Böhm-Bawerk de alegar originalidade e de demolir todos os predecessores teve precedência sobre as exigências da verdade e da justiça ${ }^{32}$.

\footnotetext{
$32 \mathrm{O}$ ensaio, escrito para um seminário de Karl Knies (1821-1898) em Heidelberg foi apresentado para o austríaco F. A. Hayek pela viúva de Böhm-Bawerk em 1922-1923. Ver: GROENEWEGEN. P. D. (Ed.). The Economics of A. R. J. Turgot. The Hague: Martinus
}

Diante do mau tratamento dado por Böhm-Bawerk, é comovente ver o resumo apreciativo de Joseph Schumpeter (1883-1950) a respeito das grandes contribuições de Turgot para a Economia. Concentrando-se quase exclusivamente nas Réflections de Turgot, Schumpeter declara que a teoria de formação de preços do francês é "quase irrepreensível e, excluindo a formulação do princípio da utilidade marginal, guarda uma distância mensurável de Böhm-Bawerk" "33. A teoria da poupança, do investimento e do capital é "a primeira análise séria dessas questões" e "inacreditavelmente provou resistir. É de se duvidar que Alfred Marshall tenha ido além, J. S. Mill, por certo, não o fez. Böhm-Bawerk, sem dúvida, acrescentou-lhe um novo ramo, mas, em substância, subscreveu às proposições de Turgot" ${ }^{34}$. A teoria dos juros de Turgot "é de longe a maior proeza no campo da teoria que o século XVIII produziu, mas claramente prefigurou muito do melhor do pensamento das últimas décadas do seculo XIX"35. Contudo,

Nijhoff, 1977. p. xxix-xxx; Para a rejeição de Turgot, ver: BÖHM-BAWERK, Eugen von. Capital and Interest. South Holland: Libertarian Press, 1959, I, p. 39-45; Para a defesa austro-americana de Turgot feita por Frank Fetter (1863-1949) contra Böhm-Bawerk, ver: FETTER, Frank A. Capital, Interest and Rent: Essays in the Theory of Distribution. M. Rothbard (Ed.). Kansas City: Sheed Andrews and McMeel, 1977, p. 246; Para mais informação sobre a recepção e tratamento da teoria de juros de Turgot pelos economistas, ver: GROENEWEGEN. P. D. A Reinterpretation of Turgot's Theory of Capital and Interest. Economic Journal, Vol. 81 (June, 1971). p. 327-8; 333; 339-40; Para o péssimo tratamento de Turgot por Böhm-Bawerk segundo Schumpter, ver: SCHUMPETER, Joseph. History of Economic Analysis. Introd. Mark Perlman. London: Routledge, 1997. p. 332 n.; Sobre a controvérsia Marshall-Wicksell-Cassel sobre o tratamento da teoria dos juros de Turgot por Böhm-Bawerk, ver: GROENEWEGEN. P.D. "Turgot's Place in the History of Economic Thought: A Bicentenary Estimate". History of Political Economy, Vol. 15 (Winter 1983): 611-615.

33 SCHUMPETER, Joseph. History of Economic Analysis. Introd. Mark Perlman. London: Routledge, 1997. p. 249. [N. do T.]

${ }^{34}$ Idem. Ibidem. p. 325. [N. do.T.]

${ }^{35}$ Idem. Ibidem. p. 332. [N. do T.] 
Não seria demasiado dizer que a economia analítica levou um século para chegar onde poderia ter chegado vinte anos após a publicação do tratado de Turgot, caso seu conteúdo tivesse sido compreendido apropriadamente e absorvido por uma profissão alerta $^{36}$.

A influência de Turgot no pensamento econômico posterior foi severamente limita$\mathrm{da}$, provavelmente, em grande parte, porque seus escritos foram desacreditados de maneira injusta pelas últimas gerações por suas associações com a fisiocracia e pelo mito insidioso de que Adam Smith fundou a Economia. Aqueles economistas do século XIX que leram Turgot deixaram de perceber a importância de suas teorias de capital, juros e produção. Embora Adam Smith conhecesse Turgot pessoalmente e lesse as Réflections, sua influência sobre Smith foi aparentemente mínima; as conclusões de Smith, afora a ampla abordagem laissez-faire, foram muito diferentes. David Ricardo (1772-1823), como era de se prever, foi negligente e inábil para compreender, simplesmente admirava Turgot pelo ingrato papel político como reformador liberal. James Mill (1773-1836) teve reação semelhante. Thomas R. Malthus (1766-1834) admirava a visão de Turgot sobre valor, mas a única influência substancial de Turgot na Inglaterra foi sobre o grande defensor da teoria da utilidade subjetiva do valor, Samuel Bailey (1791-1870). Apesar de ser patente a influência em Bailey, infelizmente ele não faz referência a Turgot em sua obra, de modo que a tradição da teoria da utilidade na Grã-Bretanha não pôde redescobrir seu defensor.

É na França, no autodeclarado smithiano Jean-Baptiste Say (1767-1832), que Turgot exerceu maior influência, em especial, na teoria da utilidade subjetiva do valor, e até certo ponto, na teoria do capital e dos juros. Say foi o verdadeiro herdeiro do laissez-faire francês, da tradição protoaustríaca do século XVIII. Infelizmente, as citações que faz de Turgot minimizam sua influência e a reverência a Smith mostra-se altamente exagerada; ambas refletem a característica pós-revolucionária de Say de não desejar identificar-se muito intimamente com um monarquista pró-absolutista, um fisiocrata a favor da agricultura, tipos com os quais Turgot era desastrosamente identificado aos olhos da maioria dos franceses cultos. Daí o retorno ritualístico na direção de Adam Smith. cos

\footnotetext{
${ }^{36}$ Idem. Ibidem. p. 249. [N. do T.]
} 